\title{
Responses induced by arginine-vasopressin injection in the plasma concentrations of adrenocorticotropic hormone, cortisol, growth hormone and metabolites around weaning time in goats
}

\author{
K Katoh, M Yoshida, Y Kobayashi, M Onodera, K Kogusa \\ and Y Obara \\ Department of Animal Physiology, Graduate School of Agricultural Science, Tohoku University, Tsutsumidori, Aoba-ku, Sendai 981-8555, Japan \\ (Requests for offprints should be addressed to Y Obara; Email: yobara@bios.tohoku.ac.jp)
}

\begin{abstract}
In order to assess the biological significance of weaning and water deprivation on the control of plasma concentrations of adrenocorticotropic hormone (ACTH), cortisol, growth hormone $(\mathrm{GH})$ and metabolites in response to stimulation with arginine-vasopressin (AVP) and corticotropin-releasing hormone $(\mathrm{CRH})$, we carried out three experiments in which male goats before and after weaning were intravenously injected with AVP or CRH alone, or in combination with each other. In experiment 1 , 17-week-old (post-weaning) goats were intravenously injected with AVP or CRH alone at the doses of $0 \cdot 1,0 \cdot 3$ and $1.0 \mathrm{nmol} / \mathrm{kg}$ body weight $(\mathrm{BW})$. The AVP injection significantly and dose dependently increased plasma levels of ACTH, cortisol, GH and metabolites, whereas the injection with CRH did not cause significant increases in the levels of these parameters. In experiment 2, 4-weekold (pre-weaning) and 13-week-old (post-weaning) goats were injected with either AVP or CRH alone, followed by a combined injection of both secretagogues at a dose of $0.3 \mathrm{nmol} / \mathrm{kg} \mathrm{BW}$. Although the basal levels of the hormones and metabolites, with the exception of glucose, were greater in the 4-week-old goats, the hormone
\end{abstract}

responses induced by stimulation with AVP were weaker than those induced in 13-week-old goats. Additionally, there were no responses in any hormone patterns to $\mathrm{CRH}$ stimulation in 4-week-old goats. In experiment 3, 13week-old goats were injected with $\mathrm{CRH}$ alone followed by injection with AVP for two consecutive days of water deprivation. The animals were subjected to withdrawal of up to $20 \%$ of the total blood volume and water deprivation for up to $28 \mathrm{~h}$. However, no significant differences in plasma ACTH, cortisol or GH levels were observed between days 1 and 2. Based on these results, we concluded that: (1) AVP is a more potent stimulant than CRH in terms of its ability to induce increases in plasma levels of ACTH, cortisol and GH; (2) the role of AVP as a secretagogue of hypothalamus-pituitary-adrenal hormones is strengthened, whereas the ineffective role of $\mathrm{CRH}$ remains unaltered, by weaning; (3) acute stress such as massive withdrawal of blood volume and subjection to water deprivation may not be sufficient burdens to alter stress-related hormone levels in young goats.

Journal of Endocrinology (2005) 187, 249-256

\section{Introduction}

The release of adrenocorticotropic hormone (ACTH) is stimulated by two hypothalamic neuropeptides: corticotropin-releasing hormone $(\mathrm{CRH})$ and argininevasopressin (AVP). ACTH release in response to $\mathrm{CRH}$ stimulation is raised in a synergistic manner by AVP, oxytocin, angiotensin II, norepinephrine and epinephrine (Rivier et al. 1984, Watanabe \& Orth 1987, Engler et al. 1999). Although CRH is the most potent ACTH secretagogue in rats and humans, AVP is a more potent secretagogue than CRH in sheep and cattle (Liu et al. 1990, Senn et al. 1995, Katoh et al. 2004a).

With increases in audiovisual stress, the concentrations of AVP have been shown to increase more than those of
$\mathrm{CRH}$ in the pituitary portal circulation of sheep (Engler et al. 1999). Accordingly, the role of AVP as an activator of the hypothalamus-pituitary-adrenal gland (HPA) axis must be greater than that of CRH. ACTH is known to stimulate cortisol secretion from the adrenal cortex, which exerts lipolytic effects in combination with catecholamines released from the medulla in various mammalian species (Bentley 1998). Growth hormone (GH) as well as ACTH is a lipolytic hormone (Bauman 2000). In addition, AVP may stimulate GH secretion from the anterior pituitary, because a stress such as restricted feeding or low feeding frequency is known to raise plasma GH levels and pulse amplitude in sheep (Thomas et al. 1990, 1991). Furthermore, increased GH levels are involved in decreases in SRIF release from the hypothalamus, as chronic food 
intake restriction increases synthesis of GH-releasing hormone (GHRH), but reduces that of somatotropin releaseinhibitory factor (SRIF) in the hypothalamus of sheep (Henry et al. 2001, Thomas et al. 1991).

After birth, during the first weeks of life, ruminant neonates are obliged to take milk for several weeks until weaning, and then their intake changes to roughage, whereas this is a more gradual process for other mammals. We recently reported changes in the expression of nutrient transporters and related enzymes around weaning time in the ruminant alimentary tract. We demonstrated that weaning reduced the expression of sodium-dependent glucose transporter (SGLT1) and CD36 (a fatty acid transporter) (Hayashi et al. 2004), as well as leptin (Yonekura et al. 2002) in the gastrointestinal tract, but increased the activity of carbonic anhydrase (Kitade et al. 2002) in the parotid gland of calves and goats.

To date, it is still unknown whether or not the more potent effect of AVP is innate and/or if it changes around the time of weaning. The aim of the present study, therefore, was to compare the potency of the intravenous injection of AVP and CRH in terms of increases in plasma ACTH, cortisol and GH levels, as well as to compare their respective effects on glucose and non-esterified fatty acid (NEFA) levels. Thus, the responses of these factors before and after weaning were compared; in addition, the acute effects of a 2-day period of blood draining and water deprivation on the levels of these hormones were assessed. The overall aim of the study was therefore to determine the significance of AVP as a hormone that regulates $\mathrm{ACTH}$, cortisol and $\mathrm{GH}$ release in young goats.

\section{Materials and Methods}

The experiment was carried out according to the Guiding Principles for the Care and Use of Animals in the Field of Physiological Sciences (The Physiological Society of Japan), and the present experiment was approved by The Animal Care Committee of Tohoku University.

\section{Animals and milk intake}

Newborn Shiba goats were fed colostra from their dams for a week after birth, and then were given a commercial milk replacer for 6 weeks until weaning. The milk replacer contained skim milk, whey protein, casein, corn products, minerals and vitamins (24\% crude protein, 20\% crude fat, $10 \%$ mineral) (Meiji Feed Co., Tokyo, Japan). The animals were fed a milk replacer diet twice a day - i.e. once in the morning $(0830 \mathrm{~h})$ and once in the afternoon $(1530 \mathrm{~h})$ - until they reached 4 weeks of age, and then they were given a calf starter ration and lucerne hay cubes. On the day of the experiment, animals were not provided with the morning feed until the blood sampling was complete.

\section{Experimental design}

Animals were provided with free access to water and mineral salts during the entire study period, with the exception that they only had free access to water during the blood sampling period and except for the experimental goats in experiment 3.

In experiment 1 , eight male weaned goats (17 weeks old, $13 \cdot 2 \pm 1 \cdot 0 \mathrm{~kg}$ body weight $(\mathrm{BW}))$ were injected with AVP $(n=4)$ or CRH $(n=4)$ alone at increasing doses of $0 \cdot 1,0.3$ and $1 \cdot 0 \mathrm{nmol} / \mathrm{kg} \mathrm{BW}$ at 0,60 and $150 \mathrm{~min}$ respectively, after the injection of the first dose of each secretagogue. Blood samples $(5 \mathrm{ml}$ each) were collected every $15 \mathrm{~min}$ from $30 \mathrm{~min}$ before until $270 \mathrm{~min}$ after the first injection. For the control experiment, another three animals (17 weeks old, $13 \cdot 8 \mathrm{~kg} \mathrm{BW}$ ) were injected with physiological saline $(5 \mathrm{ml})$ at the same point in time when AVP or CRH was injected into the AVP- or $\mathrm{CRH}$-treated goats.

In experiment 2, 4-week-old (pre-weaned, $3 \cdot 3 \pm 0 \cdot 5 \mathrm{~kg} \mathrm{BW}, n=3$ ) and 13-week-old (post-weaning, $8 \cdot 3 \pm 0 \cdot 7 \mathrm{~kg} \mathrm{BW}, n=4)$ goats were injected with AVP alone at a dose of $0.3 \mathrm{nmol} / \mathrm{kg} \mathrm{BW}$. This injection was followed by a combined injection of AVP+CRH $(0 \cdot 3 \mathrm{nmol} / \mathrm{kg} \mathrm{BW}$ of each secretagogue). The injections were administered at 0 and $60 \mathrm{~min}$ respectively. Blood samples were collected every $15 \mathrm{~min}$ from $30 \mathrm{~min}$ before until $270 \mathrm{~min}$ after the first injection. In an additional experiment, 4-week-old animals $(n=3)$ were injected with $\mathrm{CRH}$, and then $\mathrm{AVP}+\mathrm{CRH}(0.3 \mathrm{nmol} / \mathrm{kg} \mathrm{BW}$ of each secretagogue) at 0 and $60 \mathrm{~min}$ respectively.

In experiment 3,13 -week-old goats $(7 \cdot 8 \pm 0 \cdot 2 \mathrm{~kg} \mathrm{BW}$, $n=4)$ were injected with CRH followed by an AVP injection $(1.0 \mathrm{nmol} / \mathrm{kg} \mathrm{BW}$ of each secretagogue) on day 1 , and the same dose and type of hormones and sampling procedure were repeated on the following day (day 2) under continuous water deprivation. Water deprivation began at the beginning of the blood sampling on day 1 (0930 h) until the blood sampling on day 2 was complete $(1300 \mathrm{~h})$. Blood sampling was carried out every $15 \mathrm{~min}$ from $30 \mathrm{~min}$ before until $210 \mathrm{~min}$ after the first injection.

\section{Blood sampling}

On the morning of the experimental day, $2 \mathrm{~h}$ prior to blood sampling, the animals were fitted with a catheter (Venula S, 20 G, Top, Tokyo, Japan) in the right jugular vein under local anesthesia. The catheter was filled with sterile iso-osmotic sodium citrate $(3 \cdot 8 \% \mathrm{w} / \mathrm{v})$ solution before and after each blood sampling. Blood samples $(5 \mathrm{ml}$ each) were taken every $15 \mathrm{~min}$, and injection of AVP, $\mathrm{CRH}$ or saline was carried out via the catheter. The total volume of blood sampled in experiments 1 and 2 was $95 \mathrm{ml}$, and $150 \mathrm{ml}$ of blood were sampled during the 2 days of experiment 3. The red blood cells were not re-injected after sampling. 
Blood samples were mixed with heparin sodium (10 U/ml; Wako Pure Chem., Osaka, Japan) and were centrifuged at $8000 \mathrm{~g}$ for $15 \mathrm{~min}$. The blood plasma was divided into five portions and stored at $-30{ }^{\circ} \mathrm{C}$ until used for the hormone and metabolite analyses.

\section{Analyses}

Plasma concentrations of ACTH and GH were determined by RIA as described previously in reports by our group (Katoh et al. 2004a,b). Cortisol levels were determined using an RIA kit (Eiken, Tokyo, Japan). The glucose and NEFA concentrations were determined using commercial kits (Glucose CII-Test and NEFA C-Test respectively, Wako Pure Chem., Osaka, Japan).

\section{Statistics}

The data were expressed as means \pm S.E.M. An unpaired Student's $t$-test (Zar 1984) was employed for analysis of the data between two groups, and Bonferroni's multiple range test following one-way ANOVA (Wallenstein et al. 1980) for the analysis of data obtained during the pre- (at $0 \mathrm{~min}$ ) and post-injection period. Statistical significance was set at $P<0 \cdot 05$.

\section{Results}

\section{Effects of CRH and AVP alone on ACTH release}

The changes in plasma ACTH, cortisol and GH levels are depicted in Fig. 1 in response to each secretagogue intravenously injected at the increasing doses of $0 \cdot 1,0 \cdot 3$ and $1.0 \mathrm{nmol} / \mathrm{kg} \mathrm{BW}$. The AVP injection significantly and dose dependently increased the levels of ACTH (Fig. 1A), cortisol (Fig. 1B), and GH (Fig. 1C), whereas the $\mathrm{CRH}$ injection did not increase the levels of these hormones. The responses induced by AVP injection were significantly greater than those induced by the CRH injection.

The plasma glucose and NEFA levels are represented in Fig. 2. Although the AVP injection significantly and dose dependently increased the concentrations of these metabolites, $\mathrm{CRH}$ injection did not induce any significant responses in these two metabolites. The responses induced by AVP injection were also significantly greater than those induced by $\mathrm{CRH}$ injection. No significant differences were found between the data for hormone (except ACTH concentrations) and metabolite concentrations in control and CRH-treated animals.

\section{Effects of weaning on ACTH response}

In the next experiment, we assessed the responses induced by AVP $(0.3 \mathrm{nmol} / \mathrm{kg} \mathrm{BW})$ alone and $\mathrm{AVP}+\mathrm{CRH}$
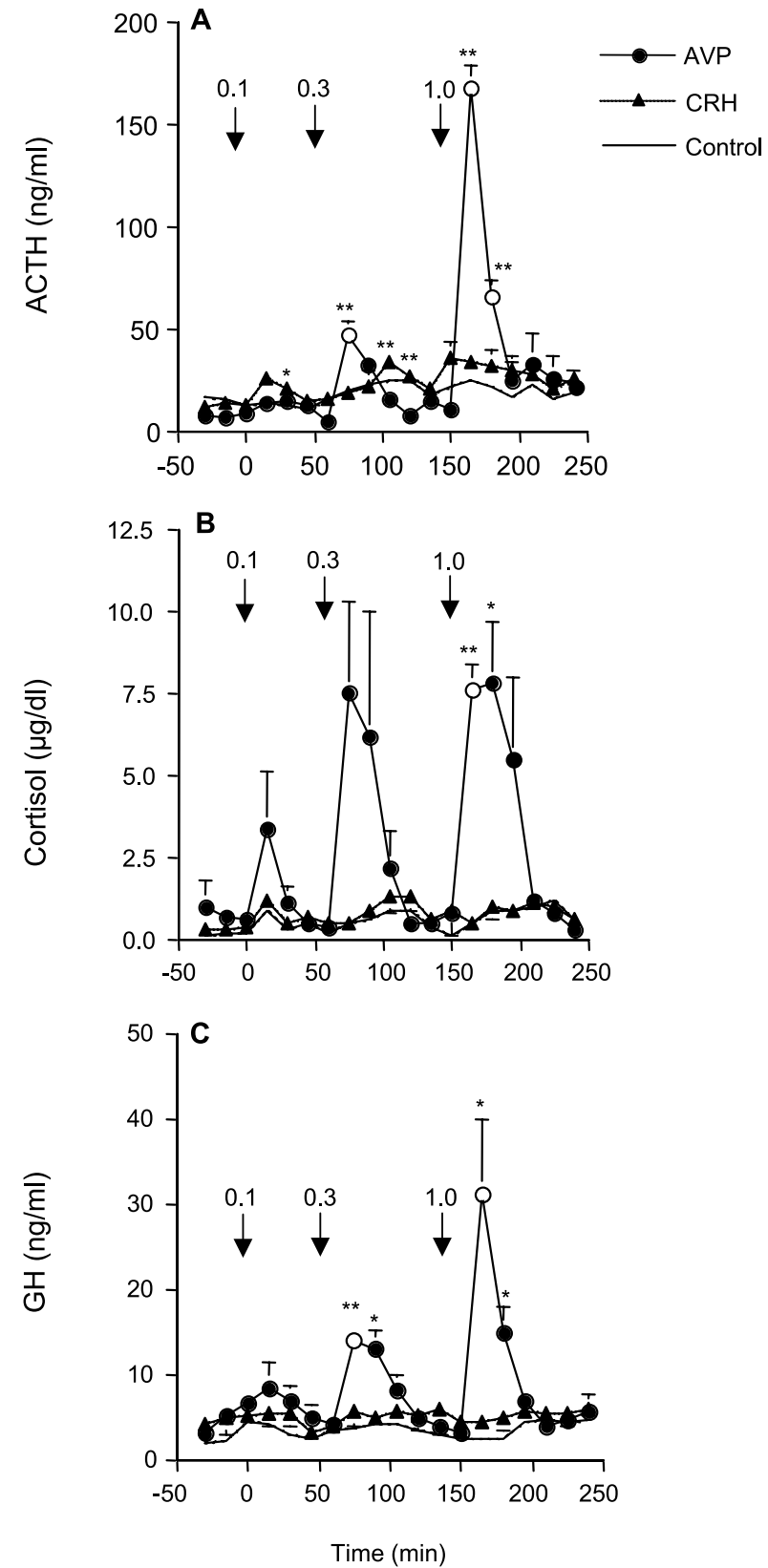

Figure 1 Effects of intravenous injection of $\operatorname{AVP}(\mathbf{\bullet})$ or $\mathrm{CRH}(\boldsymbol{\Delta})$ at increasing doses $(0 \cdot 1,0.3$ and $1 \cdot 0 \mathrm{nmol} / \mathrm{kg} \mathrm{BW})$ administered via a jugular vein catheter on plasma concentrations of ACTH (A), cortisol (B) and $\mathrm{GH}(\mathrm{C})$ in 17 -week-old goats $(n=4)$. The values are represented as the mean \pm S.E.M. Open symbols indicate a significant difference from the pre-injection level (at $0 \mathrm{~min}$ ) (Bonferroni's multiple range test). The continuous line (control, represented as the mean value) indicates the effects of an intravenous injection of physiological saline $(5 \mathrm{ml})$ administered to control goats at the same time as AVP or $\mathrm{CRH}$ injection. ${ }^{*} P<0 \cdot 05$; ${ }^{*} P<0 \cdot 01$ (AVP vs CRH, unpaired Student's $t$-test). 

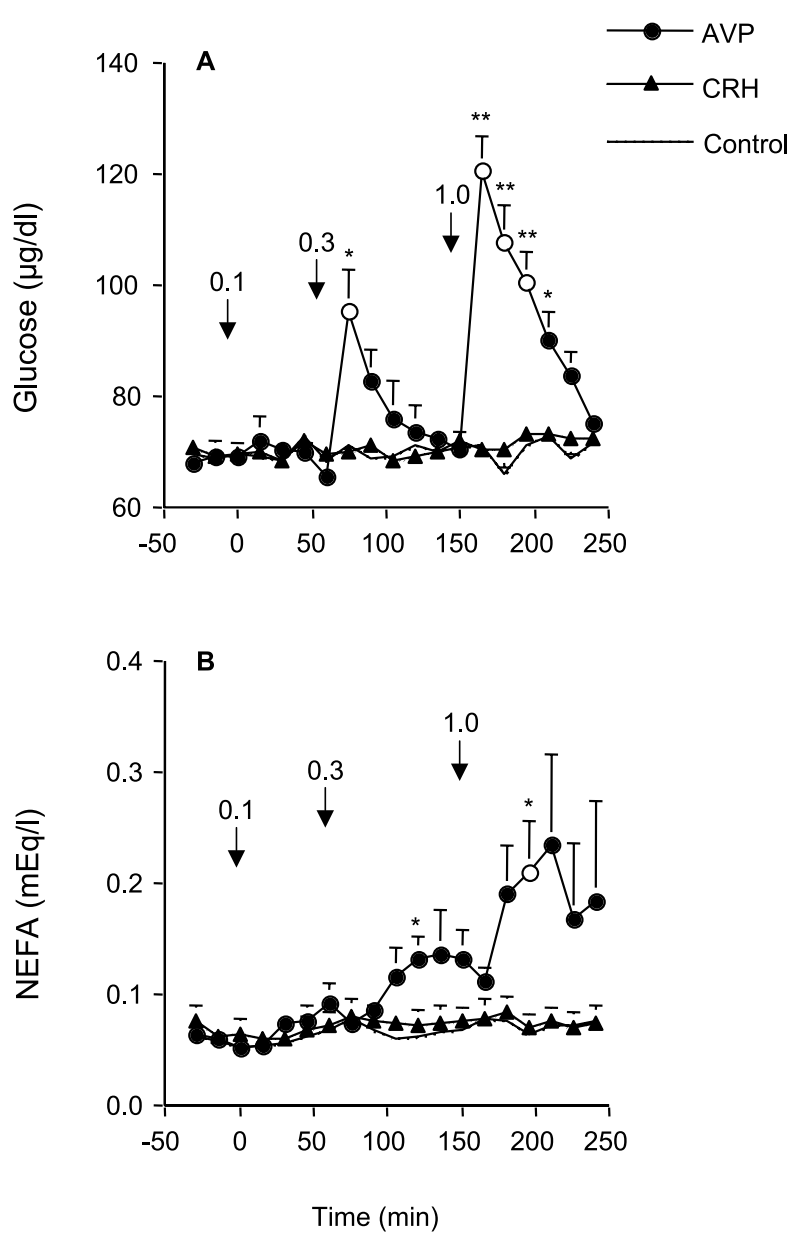

Figure 2 Effects of intravenous injection of AVP $(\bullet)$ or CRH $(\boldsymbol{\Delta})$ at increasing doses $(0 \cdot 1,0.3$ and $1.0 \mathrm{nmol} / \mathrm{kg} \mathrm{BW})$ administered via a jugular vein catheter on plasma concentrations of glucose (A) and NEFA $(B)$ in 17 -week-old goats $(n=4)$. The values are represented as the mean \pm S.E.M. Open symbols indicate a significant difference from the pre-injection level (at 0 min) (Bonferroni's multiple range test). The continuous line (control, represented as the mean value) indicates the effects of an intravenous injection of physiological saline $(5 \mathrm{ml})$ administered to control goats at the same time as AVP or $\mathrm{CRH}$ injection. ${ }^{*} \mathrm{P}<0.05$; ${ }^{* *} P<0 \cdot 01$ (AVP vs CRH, unpaired Student's $t$-test).

$(0 \cdot 3 \mathrm{nmol} / \mathrm{kg} \mathrm{BW}$ of each secretagogue) in 4-week-old (pre-weaning) and 13-week-old (post-weaning) animals (Fig. 3). The AVP injection significantly increased plasma ACTH levels in the pre-weaning animals, whereas it did not cause a significant increase in either cortisol or GH. Although the basal levels of these hormones were lower than those in the pre-weaning animals, in the postweaning animals AVP injection was found to increase the levels of all of these hormones significantly.

The combined AVP+CRH injection following AVP injection only slightly altered the levels of ACTH and cortisol in the pre-weaning goats, whereas it caused a significant increase in both hormone levels in the
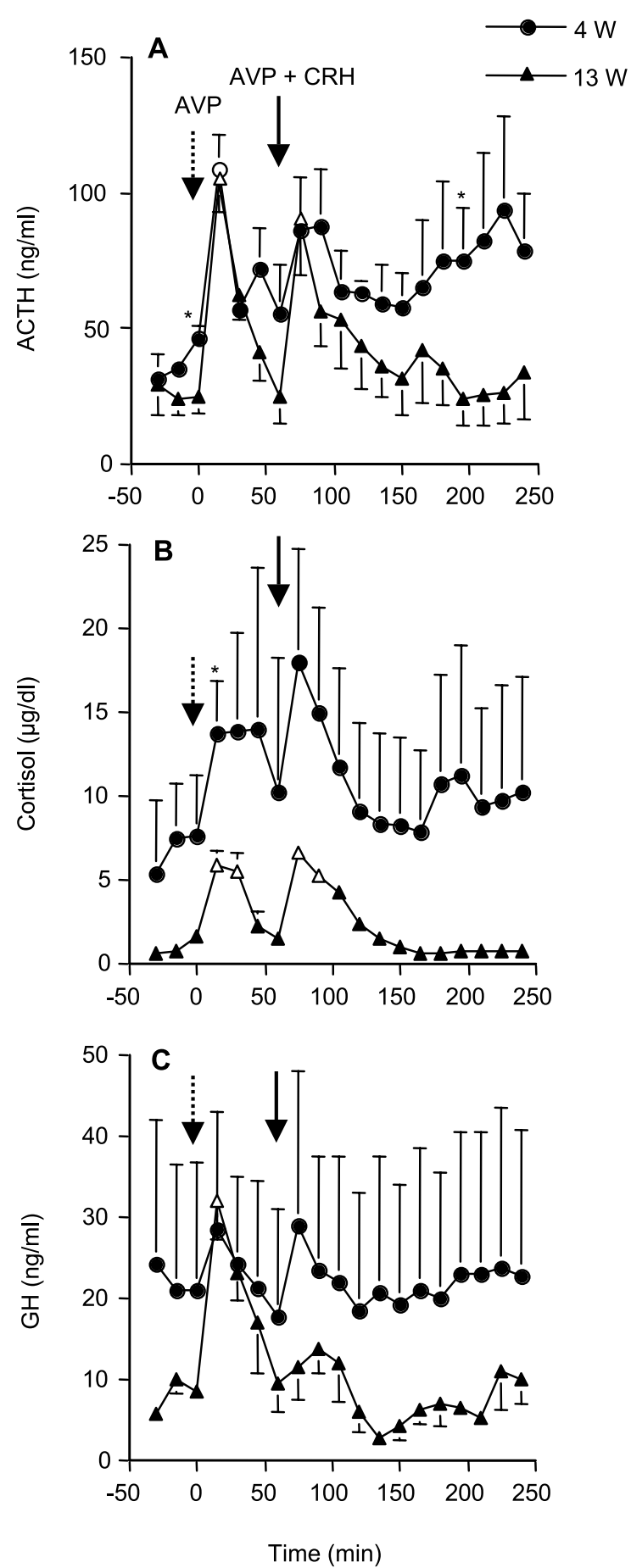

Figure 3 Comparison of the responses between 4- $(\bullet)$ and 13-week-old ( $\boldsymbol{\Delta})$ goats in terms of the levels of ACTH (A), cortisol (B) and $\mathrm{GH}(\mathrm{C})$ induced by the intravenous injection of AVP alone and $\mathrm{AVP}+\mathrm{CRH}$ administered via a jugular vein catheter $(0.3 \mathrm{nmol} / \mathrm{kg}$ BW of each secretagogue) ( $n=3$ or 4$)$. Open symbols indicate a significant difference from the pre-injection level (at $0 \mathrm{~min}$ ) (Bonferroni's multiple range test). * $P<0 \cdot 05$ (4- vs 13-week-old goats, unpaired Student's t-test). 


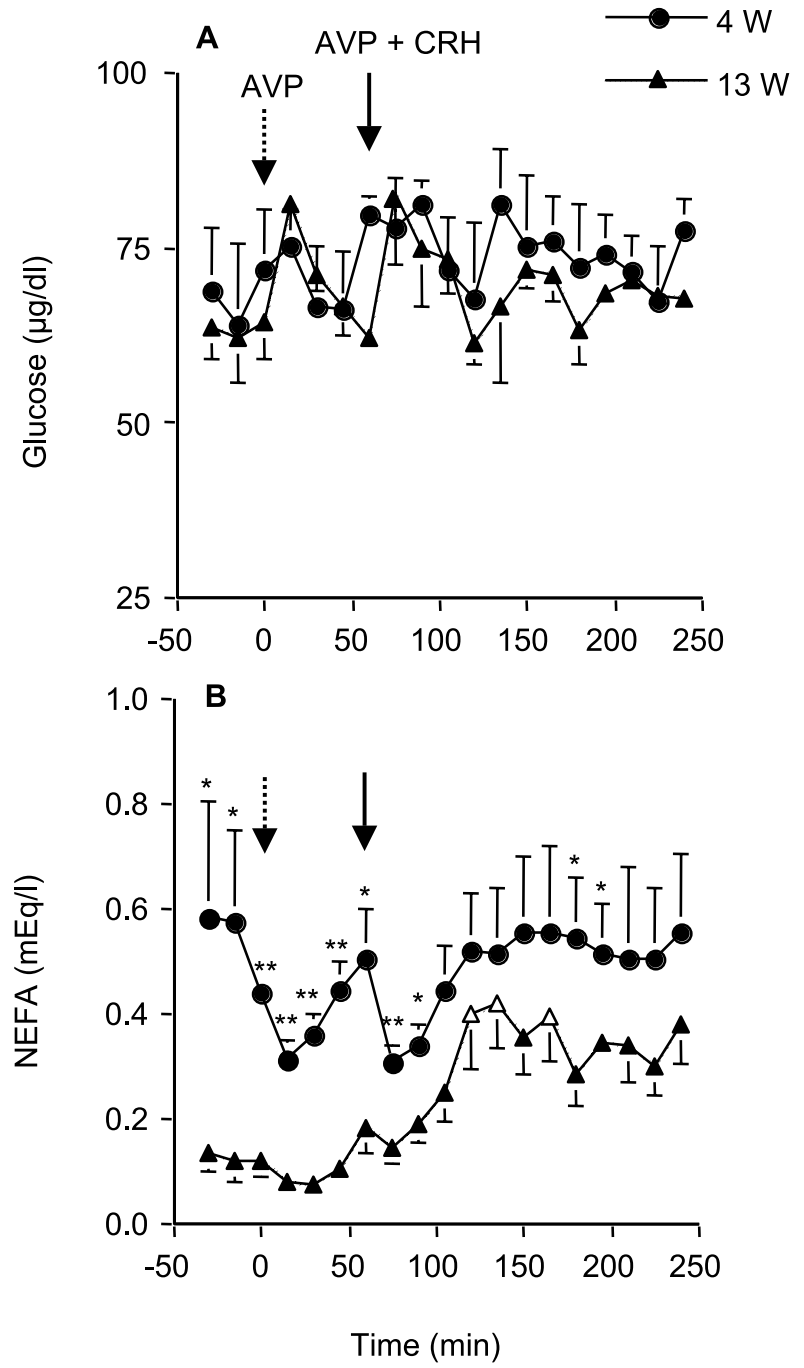

Figure 4 Comparison of the responses between 4- (-) and 13-week-old $(\boldsymbol{\Delta})$ goats in terms of the glucose (A) and NEFA (B) levels induced by the intravenous injection of AVP alone and $\mathrm{AVP}+\mathrm{CRH}$ administered via a jugular vein catheter $(0.3 \mathrm{nmol} / \mathrm{kg}$ BW of each secretagogue) ( $n=3$ or 4 ). Open symbols indicate a significant difference from the pre-injection level (at $0 \mathrm{~min}$ ) (Bonferroni's multiple range test). ${ }^{*} P<0 \cdot 05 ;{ }^{*} P<0 \cdot 01$ (4- vs 13-week-old goats, unpaired Student's t-test).

post-weaning goats. However, there were no significant changes in $\mathrm{GH}$ levels in response to the $\mathrm{AVP}+\mathrm{CRH}$ injection following the AVP injection.

There was neither significant difference in the basal glucose levels nor significant increases induced by AVP and $\mathrm{AVP}+\mathrm{CRH}$ injection in pre- and post-weaning animals (Fig. 4A). The basal NEFA levels in the preweaning animals were significantly greater than those in the post-weaning animals. In the post-weaning animals, the injection of AVP+CRH led to significantly increased levels of NEFA, whereas in the pre-weaning animals,
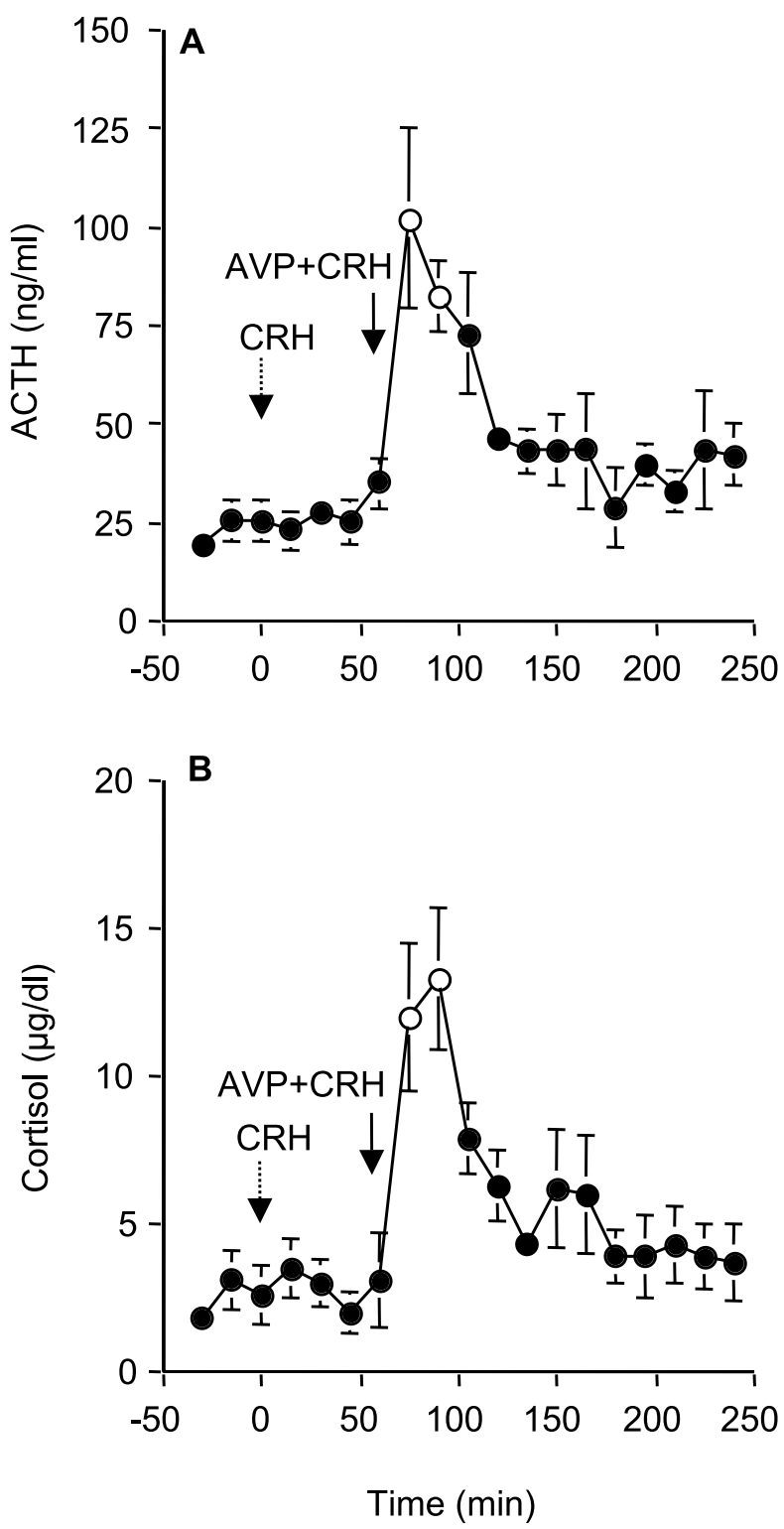

Figure 5 Effects of the intravenous injection of $\mathrm{CRH}$ and $\mathrm{AVP}+\mathrm{CRH}$ administered via a jugular vein catheter $(0 \cdot 3 \mathrm{nmol} / \mathrm{kg}$ BW for each secretagogue) on the plasma concentrations of ACTH (A) and cortisol (B) in 4-week-old goats $(n=3)$. The values are represented as the mean \pm S.E.M. Open symbols indicate a significant difference from the pre-injection level (at $0 \mathrm{~min}$ ) (Bonferroni's multiple range test).

AVP alone and the combined injection did not cause significant changes in NEFA levels (Fig. 4B).

Figure 5 depicts the ACTH and cortisol responses to the injection of $\mathrm{CRH}$ alone and AVP+CRH $(0 \cdot 3 \mathrm{nmol} / \mathrm{kg}$ $\mathrm{BW}$ of each secretagogue) in pre-weaning animals. The $\mathrm{CRH}$ injection did not lead to a significant increase in either ACTH or cortisol levels, whereas the combined 
injection was associated with a significant increase in the levels of both hormones.

\section{Effects of water deprivation on ACTH release}

The changes in plasma ACTH, cortisol and GH in response to CRH and then AVP injection $(1.0 \mathrm{nmol} / \mathrm{kg}$ BW of each secretagogue) were assessed during water deprivation, to which the goats were subjected for 2 days, i.e. from the onset of the blood sampling on day 1 to the end of the sampling period on day 2 (Fig. 6). Despite the total volume of blood drawn $(150 \mathrm{ml}$ over the 2-day period), and the duration of water deprivation (up to $28 \mathrm{~h}$ ), there were no significant changes between days 1 and 2 in these hormone levels in response to injection with both CRH and AVP.

\section{Discussion}

In this study, we demonstrated that the intravenous injection of AVP $(0 \cdot 1,0 \cdot 3$ and $1 \cdot 0 \mathrm{nmol} / \mathrm{kg} \mathrm{BW})$ significantly and dose dependently increased the levels of ACTH, cortisol and GH in post-weaning goats. The $\mathrm{CRH}$ injection did not evoke any significant changes in ACTH, cortisol or GH levels. Previous findings have indicated that $\mathrm{CRH}$ is the most potent $\mathrm{ACTH}$ secretagogue in rats and humans, whereas AVP is the most potent in sheep and cattle (Engler et al. 1999). The effect of AVP as a potent ACTH secretagogue may be a common feature among ruminants because, as shown in the present study, AVP was a potent ACTH secretagogue in goats as well as in sheep and cattle. At present, it remains unknown why AVP is such a potent ACTH secretagogue in ruminants; however, it is possible that these animals exhibit unique water metabolism and/or water retention ability. Here, it was observed that AVP injection under water-deprivation conditions did not alter the basal or AVP-induced responses of goats, as shown in Fig. 6. The blood volume drawn from each animal was $150 \mathrm{ml}$ over the course of 2 days, and the duration of water deprivation was for a period of up to $28 \mathrm{~h}$, over two successive days. If the total blood volume is estimated at $8 \%$ of the BW, the volume of blood drawn in this study $(150 \mathrm{ml})$ should have amounted to more than $20 \%$ of the total blood volume. Although the biological significance of AVP in the regulation of ACTH secretion remains to be clarified, it is possible that the volume of blood withdrawn has different effects on HPA axis activity in pre-weaned and post-weaned goats, depending on the weight of the animal. Another explanation for the observed lack of an effect of water deprivation on the HPA axis responsiveness to CRH and AVP might be a specific effect of the types of stress applied in this study.

We also demonstrated that the responses of ACTH and other hormones change around the time of weaning,
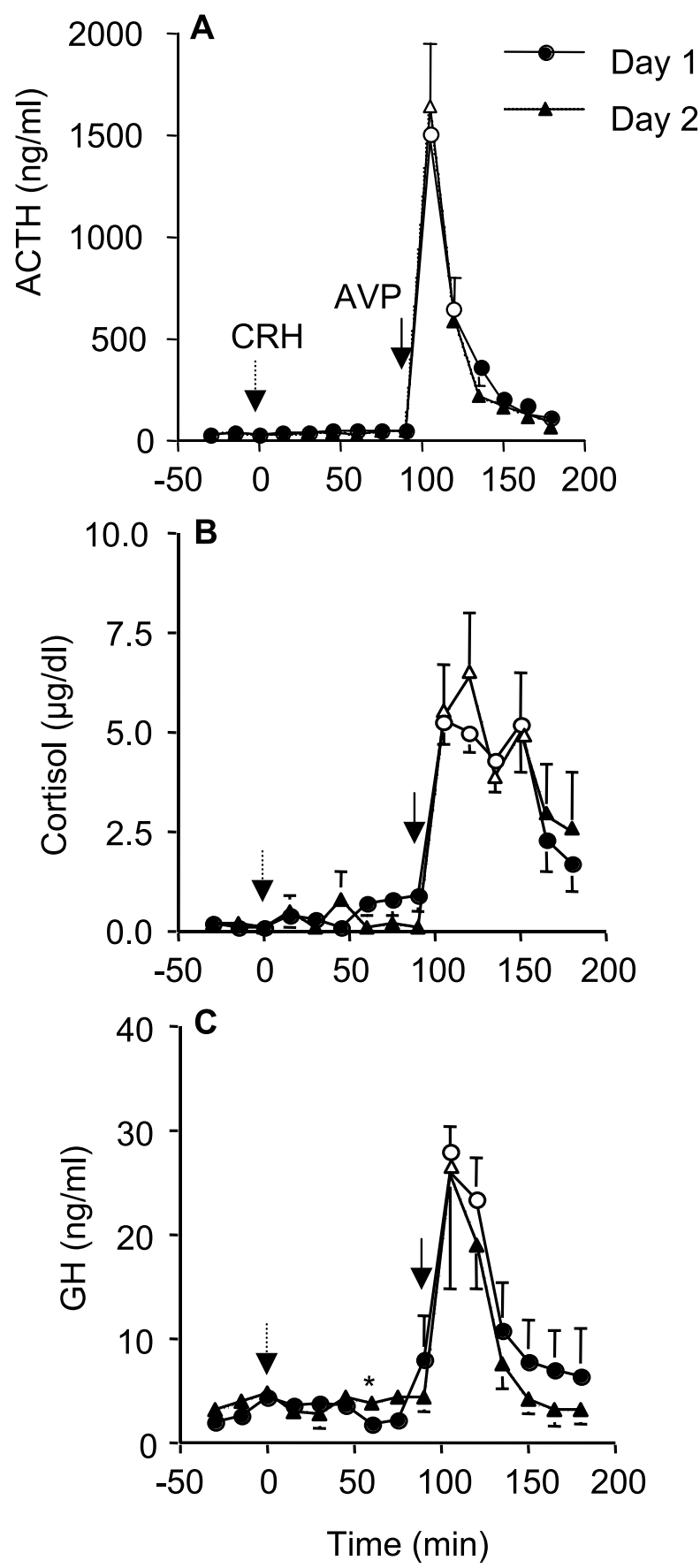

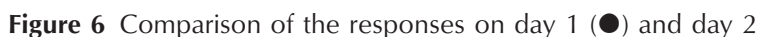
$(\boldsymbol{\Delta})$ induced by the intravenous injection of $\mathrm{CRH}$ and AVP administered via a jugular vein catheter $(1.0 \mathrm{nmol} / \mathrm{kg}$ BW of each secretagogue) with respect to the plasma concentrations of ACTH (A), cortisol (B) and $\mathrm{GH}(\mathrm{C})$ in 13-week-old goats $(n=4)$. The values are represented as the mean \pm S.E.M. Open symbols indicate a significant difference from the pre-injection level (at $0 \mathrm{~min}$ ) (Bonferroni's multiple range test). 
although AVP was found to be a more potent secretagogue than CRH in terms of HPA hormone secretion. This finding may indicate the possibility that the ACTH response to AVP stimulation is gradually established along with the aging process. In the somatotropic axis, the postprandial GH response has been shown to differ before and after weaning in neonatal calves (Katoh et al. 2004b). That is, postprandial plasma GH levels significantly increased following a feeding with milk but these levels decreased following a concentrate thay feeding. Thus, the secretion of pituitary hormones such as GH and ACTH may be altered and gradually established after weaning.

Here, we have demonstrated for the first time that AVP injection increased not only HPA hormones such as ACTH and cortisol, but also GH. It is well known that stressors such as restricted feeding or low feeding frequency increase plasma GH levels and, in particular, the pulse amplitude in sheep (Thomas et al. 1990, 1991). These responses are due to the inhibition of the release and synthesis of SRIF as well as to an increase in GHRH synthesis in the hypothalamus of sheep (Henry et al. 2001, Thomas et al. 1991). However, the increased GH levels observed here may not have been due to increases in ACTH and/or cortisol levels, as no significant differences were observed in terms of when these hormones reached peak values (Figs 1, 3 and 6).

The AVP injection induced a significant increase in NEFA levels at the dose of $1 \mathrm{nmol} / \mathrm{kg} \mathrm{BW}$. This result may have been due to the increase in ACTH levels, because ACTH, as well as other HPA hormones, possesses lipolytic activity in various mammalian species (Bentley 1998). We recently demonstrated that various fatty acids suppress ACTH release induced by CRH stimulation in rat anterior pituitary cells (Katoh et al. 2004a). A significant inhibitory effect of caprylate was found to be concentration dependent, and was even seen at $1 \mu \mathrm{mol} / \mathrm{l}$. These findings indicate the possibility of a feedback regulation system between ACTH and fatty acids. It has also been reported in the ruminant in vivo and in vitro that GH release is inhibited by various fatty acids (Hertelendy \& Kipnis 1973, Reynaert et al. 1975, Sartin et al. 1988, Coxam et al. 1989, Estienne et al. 1989, Matsunaga et al. 1998, 1999, Ishiwata et al. 2000).

Vasopressin, as well as beta-adrenergic agonists, is known to stimulate glycogen breakdown in a $\mathrm{Ca}^{2+}$ dependent mechanism in hepatocytes (Exton 1981). These agonists also stimulate lactate output in the liver of fed rats (Hue et al. 1978, 1981). However, vasopressin is reported to markedly suppress NEFA levels in rats (Caisova et al. 1980). These findings indicate the possibility that changes in glucose (but not NEFA) levels induced by the AVP injected in the present study were, at least in part, a direct effect of vasopressin on hepatocytes.

The synergistic action induced by the combination of $\mathrm{CRH}$ and AVP has been reported in the rat in vivo and in vitro (Gillies et al. 1982, Katoh et al. 2004a). We found that a synergism in ACTH release was also reproduced in ovine anterior pituitary cells, but this response was not found to occur in parallel with increases in cellular calcium ion concentrations (K Katoh and D Engler, unpublished data). Although these findings suggest the possibility that synergism in ACTH release occurs in a variety of animal species, despite unknown cellular mechanisms, it remains unclear whether or not this synergism occurs in young goats. The present findings may have been due to the prompt decrease in ACTH secretion when AVP was injected in step-wise increasing doses in the present study. This assumption is made because the ACTH peak value induced by the first AVP trial (Fig. 6) was 10 times greater than that observed in the third trial (Fig. 1) at the dose of $1 \cdot 0 \mathrm{nmol} / \mathrm{kg} \mathrm{BW}$, even though similar responses in cortisol and GH levels were observed.

In summary, AVP is a more potent secretagogue than $\mathrm{CRH}$ in terms of its ability to induce increased plasma levels of ACTH, cortisol and GH; moreover, the role of AVP as a secretagogue of HPA hormones is strengthened by weaning in young goats. However, the acute stressors applied here - i.e. a massive withdrawal of blood, and water deprivation over the course of two consecutive days - may not have been sufficient to alter stress-related hormone levels in young goats.

\section{Acknowledgments}

We gratefully acknowledge Dr M T Rose (University of Wales, UK) and Professor Dennis Engler (Monash University, Australia) for their kind advice on this manuscript, and Dr B J Canny (Monash University, Australia) for the provision of the antibody to human ACTH (BC7). This manuscript includes part of a Master's Thesis by M Yoshida submitted to Tohoku University in 2004.

\section{Funding}

The authors declare that there is no conflict of interest that would prejudice the impartiality of this scientific work.

\section{References}

Bauman DE 2000 Regulation of nutrient partitioning during lactation: homeostasis and homeorhesis. In Ruminant Physiology (Digestion, Metabolism, Growth and Reproduction), pp 311-328. Ed. PB Cronje. Oxford, UK: CABI Publishing.

Bentley PJ 1998 Hormones and nutrition. In Comparative Vertebrate Endocrinology, 3rd edn, pp 223-268. Ed. PJ Bentley. Cambridge, UK: Cambridge University Press.

Caisova D, Stajner A \& Suva J 1980 Modification of fat and carbohydrate metabolism by neurohypophyseal hormones. 1. Effect of lysine-vasopressin on non-esterified fatty acid, glucose, triglyceride and cholesterol levels in the serum of female rats. Endokrinologie 76 315-325. 
Coxam V, Davicco M-J \& Bariet J-P 1989 Effect of triglycerides on growth hormone $(\mathrm{GH})$-releasing factor-mediated $\mathrm{GH}$ secretion in newborn calves. Domestic Animal Endocrinology 6 389-393.

Engler D, Redei E \& Kola I 1999 The corticotropin-release inhibitory factor hypothesis: a review of the evidence for the existence of inhibitory as well as stimulatory hypophysiotropic regulation of adrenocorticotropin secretion and biosynthesis. Endocrine Reviews $\mathbf{2 0}$ 460-500.

Estienne MJ, Schillo KK, Green MA \& Boling JA 1989 Free fatty acids suppress growth hormone, but not luteinizing hormone, secretion in sheep. Endocrinology 125 85-91.

Exton JH 1981 Molecular mechanisms involved in alpha-adrenergic responses. Molecular and Cellular Endocrinology 23 233-264.

Gillies GE, Linton EA \& Lowry PJ 1982 Corticotropin releasing activity of the new CRF is potentiated several times by vasopressin. Nature 299 355-357.

Hayashi H, Yonezawa T, Kanetani T, Katoh K \& Obara Y 2004 Expression of mRNA for nutrient transporters in the gastrointestinal tract before and after weaning. Journal of Animal and Feed Science $\mathbf{1 3}$ Suppl 1 405-408.

Henry BA, Rao A, Tilbrook AJ \& Clarke IJ 2001 Chronic food-deprivation alters the expression of somatostatin and growth hormone-releasing hormone in the ovariectomized ewe. Journal of Endocrinology 170 R1-R6.

Hertelendy F \& Kipnis PM 1973 Studies on growth hormone secretion: V. Influence of plasma free fatty acid levels. Endocrinology $92402-410$.

Hue L, Feliu JE \& Hers HG 1978 Control of gluconeogenesis and of enzymes of glycogen metabolism in isolated rat hepatocytes Biochemical Journal 176 791-797.

Hue L, Van Schaftingen E \& Blackmore PE 1981 Stimulation of glycolysis and accumulation of a stimulator of phosphofructokinase in hepatocytes incubated with vasopressin. Biochemical Journal 194 1023-1026.

Ishiwata H, Nagano M, Sasaki Y, Chen C \& Katoh K 2000 Short-chain fatty acids inhibit the release and content of growth hormone in anterior pituitary cells of the goat. General and Comparative Endocrinology 118 400-406.

Katoh K, Asari M, Ishiwata H, Sasaki \& Obara Y 2004a Saturated fatty acids suppress adrenocorticotropic hormone (ACTH) release from rat anterior pituitary cells in vitro. Comparative Biochemistry and Physiology A 137 357-364.

Katoh K, Furukawa G, Kitade K, Katsumata N, Kobayashi Y \& Obara Y 2004b Postprandial changes in plasma GH and insulin concentrations, and responses to stimulation with GH-releasing hormone $(\mathrm{GHRH})$ and GHRP-6 in calves around weaning. Journal of Endocrinology 183 497-505.

Kitade K, Takahashi K, Yonekura S, Katsumata N, Furukawa G, Ohsuga S, Nishita T, Katoh K \& Obara Y 2002 Effects of nutritional conditions around weaning on carbonic anhydrase activity of the parotid gland and ruminal and abomasal epithelia of Holstein calves. Journal of Comparative Physiology B 172 379-385.

Liu J-P, Robinson PJ, Funder JW \& Engler D 1990 The biosynthesis and secretion of adrenocorticotropin by the ovine anterior pituitary is predominantly regulated by arginine vasopressin (AVP). Evidence that protein kinase C mediates the secretion of AVP. Journal of Biological Chemistry 265 14136-14142.

Matsunaga N, Wakiya M, Ro, SG, Hirota M, He ML, Hidaka S \& Hidari H 1998 Effect of cholinergic blockade on inhibited GH secretion by feeding and intraruminal SCFA infusion in sheep. American Journal of Physiolog $\gamma$ - Endocrinolog $\gamma$ and Metabolism 274 E45-E51.

Matsunaga N, Arakawa NT, Goka T, Nam KT, Ohneda A, Sasaki Y \& Katoh K 1999 Effects of ruminal infusion of volatile fatty acids on plasma concentration of growth hormone and insulin in sheep. Domestic Animal Endocrinology 17 17-27.

Reynaert R, de Paepe M, Marcus S \& Peeters G 1975 Influence of serum free fatty acid levels on growth hormone secretion in lactating cows. Journal of Endocrinology 66 213-224.

Rivier C, Rivier J, Mormede P \& Vale W 1984 Studies of the nature of the interaction between vasopressin and corticotropin-releasing factor on adrenocorticotropin release in the rat. Endocrinology 115 882-886.

Sartin JL, Bartol FF, Kemppainen RJ, Dieberg G, Buxton D \& Soyoola E 1988 Modulation of growth hormone-releasing factor stimulated growth hormone secretion by plasma glucose and free fatty acid concentrations in sheep. Neuroendocrinology 48 627-633.

Senn M, Maier PM \& Langhans W 1995 ACTH, cortisol and glucose responses after administration of vasopressin in cattle and sheep. Journal of Comparative Physiology B 164 570-578.

Thomas GB, Mercer JE, Karalis T, Rao A, Cummins JT \& Clarke IJ 1990 Effect of restricted feeding on the concentrations of growth hormone $(\mathrm{GH})$, gonadotropins, and prolactin $(\mathrm{PRL})$ in plasma, and on the amounts of messenger ribonucleic acid for $\mathrm{GH}$, gonadotropin subunits, and PRL in the pituitary glands of adult ovariectomized ewes. Endocrinology 126 1361-1367.

Thomas GB, Cummins JT, Francis H, Sudbury AW, McCloud PI \& Clarke IJ 1991 Effect of restricted feeding on the relationship between hypophysial portal concentrations of growth hormone (GH)-releasing factor and somatostatin, and jugular concentrations of GH in ovariectomized ewes. Endocrinology 128 1151-1158.

Wallenstein S, Zucker CL \& Fleiss JL 1980 Some statistical methods useful in circulation research. Circulation Research 47 1-9.

Watanabe T \& Orth DN 1987 Detailed kinetic analysis of adrenocorticotropin secretion by dispersed rat anterior pituitary cells in a microperifusion system: effects of ovine corticotropin-releasing factor and arginine vasopressin. Endocrinology 121 1133-1145.

Yonekura S, Kitade K, Furukawa G, Takahashi K, Katsumata K, Katoh K \& Obara Y 2002 Effects of aging and weaning on RNA expression of leptin and CCK receptors in the calf rumen and abomasums. Domestic Animal Endocrinology 22 25-35.

Zar JH 1984 Biostatistical Analysis. Englewood Cliffs, New Jersey: Prentice-Hall Inc.

Received in final form 9 August 2005

Accepted 10 August 2005

Made available online as an Accepted Preprint 24 August 2005 